\title{
Os dados governamentais e a violência letal contra lésbicas no Brasil
}

Government data and lethal violence against lesbians in Brazil

\author{
Camila Rocha Firmino' (iD 0000-0002-1292-3772
}

'Universidade Federal de Santa Catarina, Programa de Pós-Graduação em Antropologia, Florianópolis, SC, Brasil. 88040-900-ppgas@contato.ufsc.br

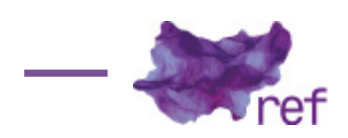

PERES, Milena; SOARES, Suane; MARQUES, Maria Clara.

Dossiê sobre lesbocídio no Brasil: de 2014 até 2017.

Rio de Janeiro: Livros llimitados, 2018. 114 p.

A partir das informações trazidas pelo Dossiê sobre lesbocídio no Brasil: de 2014 até 2017, esta resenha busca refletir sobre como tais dados podem incidir na produção de registros administrativos e dados governamentais. Desde minha atuação profissional no Poder Executivo Federal, trabalhando com indicadores sociais sobre desigualdade de gênero, pude constatar a pouca disponibilidade de dados estatísticos sobre a realidade das lésbicas. Embora o Plano Nacional de Políticas para as Mulheres considere a diversidade e a desigualdade entre as mulheres e tenha um capítulo dedicado ao tema: "Enfrentamento do racismo, sexismo e lesbofobia" (BRASIL, 2013), essa preocupação não havia se traduzida em uma abordagem da especificidade da violência contra lésbicas. Nesse sentido, ressalta-se a importância de pesquisas como o Dossiê... para a produção de dados governamentais, bem como para o desenvolvimento e aprimoramento de políticas públicas. O documento delineia um problema: o assassinato de lésbicas por motivação de ódio a um determinado tipo de mulher. No entanto, conforme argumentam as autoras, nem a Lei 1 1.340/2006 (Lei Maria da Penha) nem a Lei 13.104/2015 (Lei do feminicídio) abordam a violência contra lésbicas.

A pesquisa que resultou no Dossiê... é inovadora tanto por ser uma das primeiras a se debruçar sobre o tema quanto ao emprego do conceito lesbocídio. Em entrevista ao Portal Catarinas (Milena PERES; Suane SOARES; Maria Clara MARQUES, 2018) as autoras contaram que a ideia inicial da pesquisa foi proposta por Milena Cristina Carneiro Peres que, após o assassinato brutal de Luana Barbosa', ao buscar informações sobre quem seriam as "outras Luanas" se deparou com a ausência de estudos sobre o tema. Frente a essa lacuna foi idealizado juntamente com as professoras e pesquisadoras da Universidade Federal do Rio de Janeiro (UFRJ) Maria Clara Dias Marques e Suane Felippe Soares o projeto de pesquisa "Lesbocídio - As histórias que ninguém conta", iniciativa vinculada ao Núcleo de Inclusão Social (NIS) e ao grupo de pesquisa Nós: dissidências feministas da mesma instituição. O trabalho foi desenvolvido sob a Perspectiva dos Funcionamentos (PdF)

1 Em abril de 2016, Luana Barbosa, lésbica, não feminilizada, negra, mãe e periférica, morreu vítima de isquemia cerebral em decorrência de espancamento. Ela foi espancada, na esquina de sua casa, por três policiais militares do $51^{\circ}$ Batalhão de Ribeirão Preto, após recusar ser revistada por um policial homem e solicitar que a revista fosse feita por uma policial mulher. Junto de Luana estava seu filho de 14 anos que assistiu a todas as agressões que causaram a morte de sua mãe. Após ser arquivado na Justiça Militar em 2017, o caso foi reaberto na Justiça comum, a pedido do Ministério Público. No entanto, após mais de três anos do ocorrido, o caso segue ainda sem conclusão. 
elaborado por Maria Clara Dias e que "busca ampliar o contingente de concernidos morais, pois identifica que há uma disparidade entre as possibilidades de acesso aos direitos básicos por diferentes setores da população, em decorrências das desigualdades sociais, econômicas, culturais, políticas etc." (Milena PERES; Suane SOARES; Maria Clara MARQUES, 2018, p. 24).

Milena Cristina Carneiro Peres tem atuação acadêmica em ética aplicada, bioética, saúde coletiva, gênero, sexualidade e movimento de mulheres e políticas públicas. Maria Clara Dias Marques é professora titular da Universidade Federal do Rio de Janeiro vinculada ao Programa de Pós-Graduação em Filosofia e ao Programa Interinstitucional e Interdisciplinar de Pós-Graduação em Bioética, Ética Aplicada e Saúde Coletiva. Coordena o Núcleo de Ética Aplicada (NEA) e o Projeto de Extensão Núcleo de Inclusão Social (NIS) vinculados à UFRJ. Suane Felippe Soares é professora substituta em Bioética e Ética Aplicada na UFRJ, coordena o Laboratório sobre Justiça, Diretos Básicos e Políticas Públicas (JUDIPP) da mesma instituição, além de ser membra do Instituto Latinoamericano de Estudios Críticos Animales (ILECA) e da Rede LesBi Brasil.

Dentre os objetivos da pesquisa destaca-se a busca "da motivação lesbofóbica dos assassinatos, do ódio às lésbicas, e, por fim, o mapeamento dos assassinatos e suicídios de lésbicas no país" (PERES; SOARES; MARQUES, 2018, p. 25). Os dados foram obtidos por meio de monitoramento de mídias eletrônicas (jornais, sites e redes sociais). Os casos são analisados e, quando são narrados por pelo menos três fontes, são catalogados e registrados em um banco de dados com informações pertinentes como: nome e idade da vítima, cidade/estado/região onde o caso ocorreu, a profissão da vítima, o método do assassinato, o vínculo com o assassino, o sexo do assassino, o tipo de lésbica e a raça/etnia da lésbica assassinada. A etapa seguinte é o monitoramento judicial dos casos. A pesquisa possuía no momento da publicação do livro focado nos dados de 2014 a 2017 - 170 casos em monitoramento judicial, ou seja, ainda sem solução. Após essas etapas, são feitas pesquisas quanto às divulgações dos casos pelas mídias para possibilitar o acompanhamento das investigações pela sociedade civil e receber possíveis contribuições de informações relativas a tais assassinatos.

O conteúdo do trabalho aponta para a necessidade de garantia do direito à vida das lésbicas na medida que revela a existência de padrões no assassinato desse segmento da população. Nesse sentido, o termo lesbocídio é proposto como conceito que busca dar conta da especificidade desses assassinatos. "Assim, definimos lesbocídio como morte de lésbicas por motivo de lesbofobia ou ódio, repulsa e discriminação contra a existência lésbica" (PERES; SOARES; MARQUES, 2018, p. 19). Diferentemente do feminicídio, o lesbocídio não ocorre comumente no âmbito doméstico e vincula-se ao que as autoras denunciam como tentativas de extermínio de lésbicas. Isso porque, embora ambos sejam motivados por misoginia, o lesbocídio tem em particular a característica do ódio a um determinado tipo de mulher que se pretende extinguir.

A lesbofobia está, segundo as autoras, diretamente relacionada à desvalorização da vida de lésbicas, por parte da sociedade, e ao fato de sua insubmissão às regras heterossexistas que possibilitam a dominação masculina, sobretudo, das mulheres heterossexuais. Na maioria dos casos tratados pela pesquisa, as investigações desses crimes foram prejudicadas por conclusões apressadas que relacionavam os assassinatos ao tráfico de drogas em decorrência da associação, por parte do poder público, da pobreza das vítimas à criminalidade, sobretudo, nos casos que envolviam a população negra. Assim, a impunidade desses assassinatos, além de configurarem racismo institucional, representam expressões de eugenia.

Outra inovação do Dossiê... é sua abordagem quanto ao suicídio de lésbicas, o qual é compreendido como lesbocídio, pois suas causas relacionam-se ao isolamento e ao preconceito que enfrentam as lésbicas. Ademais, a publicação apresenta e relata os tipos de lesbocídio identificados: lesbocídios declarados; lesbocídios como demonstração de virilidades ultrajadas; lesbocídios cometidos por parentes homens; homens conhecidos sem vínculo afetivo-sexual ou consanguíneo; e assassinos sem conexão com a vítima.

Os comparativos gerais apontam para um preocupante aumento anual dos casos registrados desde 2013, com crescimento de $80 \%$ entre o ano de 2016 (30 casos) e 2017 (54 casos). "Em 55\% dos registros de casos de lésbicas mortas entre 2014 e 2017, as lésbicas eram não-feminilizadas [...]. Em 42\% desses mesmos registros, as lésbicas eram negras" (PERES; SOARES; MARQUES, 2018, p. 77). O fato de as notificações de mortes das brancas serem superiores ao das demais raças/etnias diverge dos dados gerais de mortalidade com recorte por raça/cor o que pode indicar uma subnotificação das mortes de lésbicas negras e indígenas. Ou seja, as mortes de negras e indígenas sequer chegam a ser noticiadas nas mídias eletrônicas monitoradas (jornais, sites e redes sociais).

Os dados também demonstram que a maioria das vítimas (assassinadas e suicidadas) estão na faixa etária de até 24 anos. Em relação aos assassinatos, $66 \%$ das vítimas eram não-feminilizadas e $63 \%$ do total de casos ocorreram nos interiores dos estados do país. Em $83 \%$ dos casos, os assassinos eram do sexo masculino. A modalidade de execução mais frequente foi por arma de fogo (47\%), seguido por faca (23\%), espancamento (13\%), estrangulamento $(9 \%)$, estupro seguido de morte (4\%), atropelamento ( $2 \%$ ) e estripamento ( $1 \%)$. Os suicídios também ocorreram com maior frequência 
nos interiores (71\%) e 69\% dos casos concentram-se na faixa etária de até 24 anos.

Na tentativa de traçar conexões entre o campo de Desenvolvimento de Políticas Sociais e o

Dossiê... destaco que a partir de uma visão geral dos dados estatísticos sobre violência contra as mulheres no Brasil a pouca disponibilidade de informações sobre mortes de lésbicas mostrou-se evidente. No que tange à violência letal contra as mulheres, a principal fonte de informações do Poder Executivo Federal é o Sistema de Informação sobre Mortalidade (SIM) do Ministério da Saúde. No entanto, não existe um recorte por orientação sexual nem por identidade de gênero no registro desses óbitos. Os dados provenientes de serviços de denúncias como o Disque 180 (violência contra a mulher) e o Disque 100 (violação de direitos humanos) também podem ser fontes de informações; entretanto, enquanto o SIM abarca a totalidade de mortes atestadas, os dados do Disque 180 e do Disque 100 referem-se às denúncias realizadas nesses canais. As informações relativas à violência letal extraídas dessas duas últimas bases não abarcam, portanto, todos os casos ocorridos no território nacional. Além disso, enquanto os relatórios do Disque 180 não mencionam a violência lesbofóbica, os relatórios do Disque 100 fornecem um pouco mais de detalhamento sobre as denúncias desse tipo de violência como, por exemplo, o local da violência, o vínculo com o agressor, entre outros (BRASIL, 2018a, 2018b, 2018c). Ainda assim, permanece a limitação desses dados uma vez que, como já mencionado, referem-se às denúncias recebidas.

A Lei 11.340/2006 (Lei Maria da Penha) prevê a criação de um sistema nacional de informações sobre violência contra mulher, contudo, esse sistema ainda não é uma realidade. Desse modo, além da violência lesbofóbica ser uma lacuna nos dados oficiais disponíveis atualmente sobre violência contra as mulheres - e que os resultados apresentados no Dossiê... demonstram muito bem -, a publicação é de interesse de toda comunidade lésbica e sua leitura se faz indispensável às agentes que planejam e executam as políticas públicas, bem como para pesquisadoras dedicadas aos estudos de gênero e feminismo. O Dossiê... revela a existência de um tipo específico de violência dirigido às lésbicas que exige responsabilização por parte do Estado por meio de políticas públicas.

A literatura especializada tem descrito as políticas públicas por meio do que se denomina 'ciclo das políticas públicas', um ciclo constituído pelas fases de formulação, de implementação, de monitoramento e de avaliação (Gabriela LOTTA; Arilson FAVARETO, 2016). Em todas essas etapas são necessários indicadores, ou seja, dados capazes de mensurar uma determinada realidade em que se pretende intervir, acompanhar ou avaliar. Segundo Paulo Januzzi indicadores são "medidas usadas para permitir a operacionalização de um conceito abstrato ou de uma demanda de interesse programático" (Paulo JANNUZZI, 2005, p. 138). Nesse sentido, produzir dados governamentais sobre as condições de vida e de morte das lésbicas é fundamental para a formulação de políticas apropriadas ao enfrentamento das violências e discriminações que nos afetam. A pesquisa sobre o lesbocídio no Brasil demonstrou a ausência de informações sobre violência letal contra lésbicas. Tal ausência de dados não é senão expressão da invisibilidade lésbica enquanto mecanismo estruturante do heteropatriarcado.

A luta pela visibilidade tem sido uma das bandeiras do movimento lésbico no Brasil e em diversas partes do mundo como estratégia de garantia de direitos. Conforme apontou Adrienne Rich (2010), a invisibilidade lésbica é um mecanismo de manutenção da heterossexualidade compulsória e, portanto, um mecanismo de dominação, não apenas das lésbicas, mas de todas as mulheres. No que tange aos dados e estatísticas governamentais, geralmente, essa invisibilidade persiste.

Por esse motivo, espera-se que essa publicação provoque o poder público para a inserção do recorte de orientação sexual e de identidade de gênero na produção dos registros administrativos e pesquisas estatísticas, sobretudo naqueles em que está demonstrada a negligência em relação às lésbicas. A produção de indicadores e de pesquisas confirmam a urgência em implementar políticas de enfrentamento ao lesbocídio e demais violências dirigidas a nós lésbicas.

\section{Referências}

BRASIL. Secretaria de Políticas para as Mulheres. Plano Nacional de Políticas para as Mulheres: 2013-2015, Brasília: Secretaria de Políticas para as Mulheres, 2013.

BRASIL. Ministério dos Direitos Humanos. Balanço Geral 2011 a $1^{\circ}$ sem de 2018 - LGBT, 2018 a. [online]. Disponível em: http://www.mah.gov.br/informacao-ao-cidadao/ouvidoria/balanco-disque100. Acesso em: 17/01/2019.

BRASIL. Ministério dos Direitos Humanos. Relatórios - Disque 180, Relatório Geral 2018, 201 8b [online]. Disponível em: http://www.mdh.gov.br/informacao-ao-cidadao/ouvidoria/relatoriosligue-180. Acesso em: 17/01/2019.

BRASIL. Presidência da República. Secretaria Nacional de Políticas para as Mulheres. Relatório Anual Socioeconômico da Mulher: 2015/2016. Brasília: Secretaria Nacional de Políticas para as Mulheres, 2018c. 
JANNUZZI, Paulo de Martino. Indicadores para diagnóstico, monitoramento e avaliação de programas sociais no Brasil. Revista do Serviço Público, v. 56, n. 2, p. 137-160, 2005. Disponível em: https://revista.enap.gov.br/index.php/RSP/article/view/222. Acesso em: 30/11/2019.

LOTTA, Gabriela; FAVARETO, Arilson. Os Arranjos Institucionais dos Investimentos em Infraestrutura no Brasil: uma análise sobre seis grandes projetos do Programa de Aceleração de Crescimento. Textos Para Discussão, Brasília: Rio de Janeiro: Ipea, n. 2253, p. 01-60, nov. 2016. Disponível em: http:// www.ipea.gov.br/portal/images/stories/PDFs/TDs/td_2253_web.pdf. Acesso em: 05/08/2019.

PERES, Milena; SOARES, Suane; MARQUES, Maria Clara. "Lesbocídio: a existência de lésbicas é uma afronta à ordem heteropatriarcal". [Entrevista concedida a] Jéssica GUSTAFSON, Portal Catarinas. 28/08/2018. Disponível em: https://catarinas.info/lesbocidio-a-existencia-de-lesbicas-e-umaafronta-a-ordem-heteropatriarcal/. Acesso em: 17/01/2019.

RICH, Adrienne. "Heterossexualidade compulsória e existência lésbica". Bagoas, v. 4, n. 5, p. 17-44, 2010.

Camila Rocha Firmino (camilafirm@gmail.com) é graduada em Ciências Sociais (Unicamp), Mestra em Antropologia Social (UFSCar), Doutoranda em Antropologia Social (UFSC) e integrante do Transes - Núcleo de Pesquisa Antropologia do Contemporâneo (UFSC). Pesquisa direitos lésbicos e as políticas públicas e de saúde e é Analista Técnica de Políiticas Sociais no Governo Federal, tendo trabalhado com políticas para as mulheres e monitoramento de indicadores de desigualdades de gênero no Observatório Brasil da Igualdade de Gênero.

\section{COMO CITAR ESSE ARTIGO DE ACORDO COM AS NORMAS DA REVISTA}

FIRMINO, Camila Rocha. "Os dados governamentais e a violência letal contra lésbicas no Brasil". Revista Estudos Feministas, Florianópolis, v. 28, n. 1, e63222, 2020.

\section{CONTRIBUIÇÃO DE AUTORIA}

Não se aplica.

\section{FINANCIAMENTO}

Não se aplica.

\section{CONSENTIMENTO DE USO DE IMAGEM}

Não se aplica.

\section{APROVAÇÃO DE COMITÊ DE ÉTICA EM PESQUISA}

Não se aplica.

\section{CONFLITO DE INTERESSES}

Não se aplica.

\section{LICENÇA DE USO}

Este artigo está licenciado sob a Licença Creative Commons CC-BY International. Com essa licença você pode compartilhar, adaptar, criar para qualquer fim, desde que atribua a autoria da obra.

\section{HISTÓRICO}

Recebido em: 18/04/2019

Revisões requeridas em: 12/06/2019

Aprovado em: 30/11/2019 